\title{
Porque o fio não se rompeu
}

\author{
Fernando Miranda \\ (Eberhard-Karls Universität Tübingen)
}

\section{RESUMO}

Com a impossibilidade de vivermos fora do espaço, a abordagem sobre este tema se torna ponto sempre presente na história da literatura. No entanto, dentro dos seus mais diversos modos de entendimento, o espaço não carrega sozinho o escopo das reflexões que o envolvem. O tempo será, também, colocado em questão. E nesta caixa de dimensões, ainda nos cabe pensar onde reside a realidade e onde residimos nós. Através da experiência do homem nas cidades, Rui Pires Cabral abre pontos importantes acerca destes tópicos.

PALAVRAS-CHAVE: espaço, realidade, subjetividade.

\section{RESUMEN}

El hecho de que sea imposible vivir fuera del espacio hace del tema punto siempre presente en la historia de la literatura. Sin embargo, en sus diversos niveles, el espacio no carga solo el escopo de las reflexiones que lo ponen como tema. También el tiempo será puesto en el argumento. Y esta caja de dimensiones todavía nos deja pensar dónde reside la realidade e dónde residimos nosotros. A través de la experiencia del hombre en el espacio, Rui Pires Cabral abre puntos importantes sobre estos tópicos.

PALABRAS CLAVE: espacio, realidad, sujetividad. 
A poesia me pôs dentro da vida.

É esta a força que fica

dentro do mundo

que ergo antes do fim

Sérgio Nazar David, "Deeper".

A relação do homem com o espaço é presença constante em qualquer literatura nacional, de qualquer período. Em certos casos, pode-se mesmo compreender através desta relação os tópicos mais frequentes de determinada época, ou, se não são tópicos muito variantes, compreender como se relacionavam com o espaço. Franco Moretti, por exemplo, dedicou uma obra ao estudo da geografia na literatura, bem como da literatura na geografia, em seu Atlas do romance europeu. Lendo romances de Jane Austen, Honoré de Balzac e Charles Dickens, entre outros, Moretti não debate apenas instâncias nacionais e políticas, através da leitura da obra literária situada em algum espaço e tempo e condicionada por inúmeros fatores linguísticos, políticos e econômicos. Mapeando os deslocamentos dos personagens nos romances, o autor busca um modo de interpretação, pelo qual estes deslocamentos ocupam algo de significante dentro da obra. Também deste modo, podemos pensar as cidades expressionistas, cujo habitante é quase catalisado no famoso quadro O Grito, de Edvard Munch. A constante dos deslocamentos em suas mais variadas motivações aparece, ainda, em relatos de viagem, que percorrem toda a história literária. Dentre os mais variados tipos de relato, encontram-se os da conquista de um determinado território por um povo, os que se centram na exploração psicológica do personagem envolvido com o estranho e os que põem em vista os processos migratórios dos exilados ou daqueles em busca de uma vida - é dizer, de um lugar - melhor.

Certas cidades frequentam o imaginário de dadas culturas de modo tão intenso que mesmo aos que jamais as visitaram as sensações do espaço moldam opiniões, comportamentos, apreciações. São capazes de discorrer sobre estas cidades com detalhes, expondo e debatendo, inclusive, o modo de vida dos seus habitantes. Para muitos, visitar estas cidades é um processo de reconhecimento. Em outro nível, o próprio morador de uma cidade a concebe, para além da relação com o espaco físico, em valores simbólicos. Eis um imenso conflito entre centro e periferia, metáfora espacial que se expandiu de tal modo que as nações passaram a ser assim separadas, sobretudo pelos aspectos socioeconômicos. Trazer uma cidade para uma definição baseada numa essência - pensa-se na oração "Uma cidade X é..." - converte-se na total impossibilidade de pensá-la, a não ser que se reconsidere o uso do "é", passando a redimensioná-lo numa esfera subjetiva, ou seja, atendendo às inúmeras variantes, como se fosse possível afirmar "és" 1. Os enunciados de uma cidade são, como na linguagem, infinitos. Aspectos espaciais, evidente, contam, como arquitetura, como a disposição das ruas, os ornamentos, os objetos úteis como lixeiras e telefones públicos, projetados dentro de planejamentos urbanísticos. O clima é fator de forte interferência, condicionando hábitos, que passam a ter relação com o tempo de uma cidade, já que os horários de vida estarão em estreita ligação com o funcionamento do comércio, do transporte público, dos lugares de lazer. Luís Quintais, em "A inútil poesia“, escreve: 
Eu não vivo numa bolha de ar em Hartford.

Como posso ser fiel aos fiéis poemas

de Stevens

sem trair esta cilada?

(Quintais, 2008, p. 88)

O poema nos provoca a repensar o real e suas múltiplas aberturas, instiga-nos a repensar nossas ideias e juízos acerca de determinadas culturas e povos. Quintais, sem nomear, abre a discussão que, a princípio, se coloca como pano de fundo filosófico em leituras de cidades. Se estamos a falar de uma cidade, onde reside a realidade? Se estamos a vivê-la, ainda assim a pergunta nos sugere algo. E, ainda, ao experenciá-las através dos sentidos, em algum momento estaremos traduzindo-os à linguagem. Na segunda estrofe, Quintais segue a provocar:

Milosz sabe que a história é tudo o que temos e que as traições maiores

são cometidas contra a história, mas também em nome dela.

(Quintais, 2008, p. 88)

Falar de uma cidade exige considerações subjetivas. Se cada expressão é transformadora, o movimento próximo não se determina, mas se relaciona com os movimentos anteriores. Portanto, o caminho que se percorre por uma cidade escapa a qualquer redução que se queira objetiva, e provoca uma quantidade tão absurda de relações, que, no instante de se instaurar o paradoxal, somos obrigados a cometer o próprio ato negado de reduzir - não de modo objetivo -, de forma que possamos pensar e refletir uma cidade, ou, mais exatamente, pensar e refletir a nossa presença numa cidade.

Poeta atento às oscilações da experiência humana no espaço, Rui Pires Cabral se apropria para seus poemas de termos comumente relacionados aos elementos citadinos, muitas vezes sem rearranjá-los em metáforas espaciais, mas sim deixando-os permanecer como termos cuja potência pode alçar e ser alçada a qualquer instante de leitura. Dois poemas que podem ser tomados como centrais são "Morada" e "Hospedarias". O próprio título dos poemas já induz a desconfiar. Enquanto o lugar da permanência se escreve com singular, o lugar de passagem se deixa em plural. Deste modo, numa leitura de mundo dito globalizado, deparar-nos-íamos com o jogo entre raiz e estrangeiro, perda da terra natal, saudade do lar, confronto linguístico, cultural. No entanto, se tomarmos atenção a dois versos de cada poema, teremos de recolocar nossa leitura em outra instância. "Morada" se abre com "Nós vivemos na cidade quase sempre perdidos" (Cabral, 2007, p. 63), enquanto em "Hospedarias" lêse, no primeiro verso da segunda estrofe, "sempre pertencemos às hospedarias“ (Cabral, 2007, p.58). Se o lugar de pertença é o da incerteza, então, parece propor Pires Cabral, estar-se num ambiente de pretensa certeza só nos traria, sim, ilusão e desconfiança. Como se o indivíduo enraizado necessitasse muito mais da busca que o flâneur, aparentemente um inquieto em busca de novas sensações, de constantes descobertas. O ser da morada ouve de "um cúmplice", "à mesa de um café", "que pouco importam/ as perdas e danos que sofremos" (Cabral, 2007, p.63). Afinal, "de qualquer modo o mundo continua“. E talvez uma das questões mais complexas dentro dos debates acerca do espaço seja a ideia de mundo. A esta altura da vida humana e de nossos conhecimentos sobre outros espaços, não mais podemos aceitar que 
mundo seja mero sinônimo de Planeta Terra. Por outro lado, os exageros do mundo em metáfora para quadro de referências de um indivíduo causam riscos imensos, um certo entendimento de, se cada um possui seu mundo, a comunhão entre eles será um fenômeno a-espacial ${ }^{2}$. Desta forma, questiona-se: o que continua? "O que poderá compensar-nos dos desgostos da jornada?" ("Hospedarias“: Cabral, 2007, p.58). Fica, sempre, o próprio indivíduo, lugar de si próprio, e ultrapassa a própria realidade. No seu livro de 1995, A superrealidade, Pires Cabral deixa claro a separação entre todas as coisas e as coisas do indivíduo. "Lá fora, a realidade era o espaço inteiro/ deitado nos vidros, o mundo caído/ para dentro do silêncio". ("Super-realidade“; Cabral, 2007, p.38). O vidro ao qual se refere o poeta é o do carro, como especificado em estrofe anterior à citada. No poema, a separação entre indivíduo e exterior é, ainda, uma passagem que não se dá em direta oposição. Um certo modo de considerar que entre realidade, super-realidade e irreal ainda existem inúmeras camadas a se percorrer, cujas fronteiras podem ser tão frágeis quanto um vidro de carro. E superar um nível ao outro sequer exige a violência. Se permanecemos na experiência de um vidro de carro, abrimos possibilidades como abri-lo, como ter uma visão refletida tanto desde dentro do carro quanto desde fora. Portanto, a super-realidade não pode ser entendida como um fenômeno que se corresponda à metafísica, como uma superação da realidade. A super-realidade, já mesmo nos diversos significados possíveis a este antepositivo, integra-se na realidade; é este indivíduo capaz de reconhecer e permanecer na sua subjetividade habitando e percorrendo espaços alheios (hospedarias, morada, corredores). Espaços que em si já se interpõem e discorrem a aparente estranha imagem de um mosaico ordenado em labirinto. Pires Cabral não desenvolve um eu-lírico atomístico, sujeito captando pelo seus sentidos as mensagens exteriores. A super-realidade não exige a misantropia como condição única para ser percorrida. Antes, o sujeito é alguém com aberturas ao externo como propulsor de suas transformações. "Eu era de terra quando me procuraste" (Cabral, 2007, p. 38) Na terra se planta, sim; mas sobre a terra se constrói, e todas as camadas que estão sob a terra permanecem sem aparência. Mas que não estejamos no risco de não considerá-las. Terremotos espalham suas marcas, e, mesmo monitorados, nem sempre são previsíveis. A terra é ainda o lugar a ser explorado; cava-se a terra. Na terra, deixamos os mortos $^{3}$.

A divisão de espaços ocasiona uma alteração na percepção do tempo. Dentro da super-realidade, o tempo é, durante a experiência do indivíduo, mais acelerado, não nas medições precisas de segundos, minutos e horas, mas sim na acentuação do nosso próprio tempo-limite, a dizer, eterna passagem rumo à morte. Tanto em "Super-realidade" - "Gastávamos depressa o tempo, perdidos/ no nosso único mapa" (Cabral, 2007, p. 38) -, quanto em "Velocidade" - "Por uma vez a velocidade foi um lugar firme/ entre as paredes. Tirei dela uma mão-cheia“" (Cabral, 2007, p.36) -, do mesmo livro, aparece esta noção. $\mathrm{O}$ ato instigante em "Velocidade" fica por conta do tempo além da super-realidade: "As árvores tinham pressa de chegar a qualquer lado". $\mathrm{Na}$ edição aqui utilizada, uma antologia, "Esplanada" é o poema a fechar a seleção do livro $A$ super-realidade. E este indício de síntese não deve ser ignorado. 
Já sabemos quantas vezes a realidade se torna imprestável para ti

e vice-versa.

O sol aquece até o futuro,

é preciso continuar a meter o coração

pelos atalhos.

(Cabral, 2007, p. 39)

A perspectiva sensorial de uma esplanada parece ser a própria escolha entre a volta à certeza ou o lançar-se ao desconhecido, se imaginamos um sujeito deixando uma construção e detendo-se diante de um terreno plano ${ }^{4}$. Porém, este jogo certeza-incerteza não passa de um mascaramento da realidade, no qual o espaço toma ares de determinante. Naquilo que resta ao indivíduo, a única opção é seguir, em qualquer que seja a direção, a partir do instante em que mesmo o retorno ao edifício não deixa de significar continuidade. Retornamos à morada e percebemos que

entre o medo e a esperança

procuramos a nossa incerta morada

e enquanto isso envelhecemos mais um dia, colhidos pelo tempo em plena queda.

(Cabral, 2007, p. 63)

Fala-se, ainda, de morte. E, se o que da morte nos interessa é o que a precede, então estamos a considerar que o espaço subjetivo é o único ao qual se possa denominar moradia. Assim, praticamente anulamos, ao menos na super-realidade, as diferenças entre morada e hospedaria ${ }^{5}$. Em todos os lugares possíveis de se estar, estaremos unicamente no nosso. Um modo de afirmação em que não nos fica mais que um caminho, haja vista que estamos tolhidos de seguir o outro durante toda sua existência. Mas não um caminho prédeterminado, escrito pelo destino; um caminho que é o que se está percorrendo, fazendo de cada ação uma escolha que resulte na anulação de outras tantas possibilidades que jamais serão conhecidas, como Calvino denominou "ramos secos", em As cidades invisiveis. E isto não é acaso, em Pires Cabral. Em "Paris", do livro Música antológica e onze cidades, de 1997, o poeta, após percorrer lugares e experenciar "um casal de aspecto aborrecido/ sentado nas dunas" ou "velhos em calções" que "riam para dentro dos copos" (Cabral 2007, p. 49), nas cervejarias, termina seu segundo dia de verão a certificar-se: "Jamais saberei se havia/ uma história à minha espera na Gare du Nord essa noite" (Cabral, 2007, p. 59).

A lírica de Rui Pires Cabral afasta-se, então, de um dos motes mais presentes na poesia do pós-guerra. Não somente por conta da própria Segunda Guerra Mundial, mas também pelos inúmeros regimes ditatoriais, caso em questão na literatura portuguesa, o exílio recebeu tratamento diverso em todas as literaturas nacionais ditas centrais, bem como nas periféricas. Além dos diversos aspectos abordados pelos poetas exilados, ainda poderemos considerar as diversas etapas passadas por este período. A subida dos regimes ditatoriais ao poder, a luta para derrubá-los, a instauração da democracia, as novas questões iniciadas a partir de então. Em um tempo, permanecia-se dentro da ditadura, noutro, a presença dela em textos era a discussão do que havia sucedido no então superado regime. Por fim, a nova etapa que se iniciava e as novas questões em aberto ${ }^{6}$. Esta dimensão histórica não se lê em Pires Cabral, a não ser na localização do que podemos conceituar como "fim de 
século". O ambiente da poética de Pires Cabral se põe justamente no instante em que o fluxo e o contrafluxo já não são tão definidos como antes. Fala-se menos de grupos que de indivíduos em deslocamento. $O$ espaço de sobrevivência, antes prevalecido na comunidade, passa a se ater no indivíduo. Não este da repetida expressão "sozinho na massa", usada para caracterizar os cidadãos das grandes cidades, sujeitos sem expressão e sem chance de se expressar. Pires Cabral aproximou-se tanto da citada "massa" a ponto de poder enxergar os rostos, sendo "um forasteiro a olhar/ na ponte" que "Uma criança atirou papéis para o rio/ e foi castigada" ("Budapeste"; Cabral, 2007, p. 48). O eu-lírico encontra e experiencia com o "tu", desveste amores e saúda amizade. "Se nos cruzássemos nas ruas desta cidade// entre desconhecidos de toda a sorte, talvez/ nos sentássemos a falar da nossa vida" (Cabral, 2007, p. 85).

De volta ao poema de Quintais, invertemos a posição, enquanto leitores, e nos questionamos como poderemos ser fiéis aos poemas de Pires Cabral se não foi esse o nosso caminho percorrido, se jamais estivemos, por exemplo, em Budapeste, Paris, ou se a Lisboa, "Cidade nova/ que cresces nos teus ramos/ para a morte" (Cabral, 2007, p. 64), não nos diz as mesmas coisas que a um poeta português. É justamente no fim deste poema, intitulado com o nome da capital portuguesa, que encontramos uma chave não apenas para a resposta, mas também para entrar no mesmo ambiente do poeta e receber sua companhia: "eu nunca caminhei/ para ninguém" (Cabral, 2007, p. 64). Os poemas de Pires Cabral ficam além da autorreferência, da necessidade de se conhecer biografias para lê-lo de modo mais correto, como qualquer obra literária que se reconheça dentro da história da sua arte. Na poética de Pires Cabral, o leitor toma lugar no sistema de transmissões, torna-se alguém capaz de atuar como receptor e transformar a mensagem, gerando-a a outros níveis e, desta vez, passando a agir como mensageiro. Um princípio que se pode aplicar, em regra geral, a qualquer situação de diálogo. No entanto, o que se torna peculiar em Pires Cabral é que o leitor não será alguém capaz apenas de recontar o que ouviu/leu, como no caso do imperador Kublai Khan, a ouvir as histórias de Marco Polo, em As cidades invisiveis. Sequer será um leitor a ter seus sentimentos despertos através das sensações convertidas em linguagem verbal do flâneur. Pires Cabral potencializa estas experiências, como dito acima, ao encontrar e dividir com o "tu" do texto suas sensações, sem, claro, deixá-las escapar do espaço subjetivo. Através das palavras "fermentadas", o poeta liberta-se ao mundo, põe seus conflitos ao exterior - "é uma guerra e está dentro de mim" ("Cantiga"; Cabral, 2007, p. 33) -, dividindo estilhaços por onde seja lido. Coloca em questionamento, uma vez mais, as frágeis perspectivas da realidade. "Com o que sobra/ invento outra mitologia" (Cabral, 2007, p. 33).

Mitologia que não está isolada do mundo, nem da realidade, nem da tradição poética. É outra vez Quintais, no poema acima citado, quem nos parece guiar a esta leitura: "A corda é invisível/ e eu procuro-a/ sem método." (Quintais, 2008) Nas transmissões entre sujeitos, indivíduos ligados ao espaço, descobrimos nosso tempo do real e de seus demais níveis. Se estavam os poetas portugueses de fim de século a se dizer sem qualidades, nada mais justo, então, que nos deixem a inútil poesia. E toda a inutilidade de não pretendê-la.

Aquele que me lê / deverá acreditar:

deverá acreditar / que eu vivo

perscrutando as águas / mas dentro delas.

(Quintais, 2008, p, 89) 
NOTAS

1. Dado que a forma "és" corresponde à segunda pessoa do singular do verbo ser, a proposta pode gerar confusão bem como provocar uma ideia de cidade enquanto elemento a ocupar o lugar do tu, transformando a relação do indíviduo com a cidade em dialogismo. A forma consagrada para o plural - "são" - nos podería levar a uma percepção de agrupamento, de um todo que convivesse no mesmo direcionamento.

2. Leva-se, aqui, o termo em afastamento de siginifcados, sim, possíveis. No entanto, inacessíveis no tocante à obra cabralina.

3. A metáfora como compreensão do mundo coloca a linguagem em estrita relação com o meio, a dizer, com o espaço. Fenômenos da natureza serviram ao homem para a elaboração de seus modos de construir. No caso das cidades já erguidas, cabe-nos a questão acerca de uma outra ordem. Se ainda nos aproximarmos do tema geográfico, estaremos diante da coexistência de espaço natural e espaço construído, em certa medida conflito, em certa medida complemento. Não fica exagerado recordar que mesmo o espaço construído se apropria de elementos naturais. É o caso da ornamentação com plantas, das ruas arquitetadas com árvores. Se bem nos torna óbvio, nos dias de hoje, recordamos que o tema recebeu grande impulso através de Alexander von Humboldt (1769-1859).

4. Outra vez, Rui Pires Cabral deixa no leitor a capacidade de experiência própria. A visão da esplanada pode muito bem ser invertida, ou seja, indicar o sujeito que, após atravessar o terreno plano e de horizontes aparentemente inatingíveis, vê-se diante de uma construção. A imagem de um indivíduo diante de uma construção, com o terreno plano às suas costas, recorda-nos o personagem kafkiano de "O Castelo".

5. Este trabalho não comporta espaço para a apreciação de temas correlacionados, como a ideia de pertencimento a um determinado espaço geográfico (nação, região, povoado) ou a uma língua. Cabe-nos, entretanto, manter-nos atentos a estes fatores, e o quanto eles podem interferir nas relações de realidade, super-realidade e irreal.

6. Em entrevista ao jornal "Die Zeit", o historiador alemão Heinrich August Winkler retoma o debate sobre o "fim da história“, em que alguns historiadores centram a ideia da solução dos problemas do século a partir dos eventos iniciados em 1989/90. Winkler relembra que, ao solucionar problemas, a humanidade ainda se depara com os novos surgidos, e o mecanismo de mudança permenece.

\section{REFERÊNCIAS BIBLIOGRÁFICAS}

CALVINO, Italo. Le città invisibili. Milano: Oscar Mondadori, 2008.

CABRAL, Rui Pires. Portugal, 0 vol. 2. Seleção e organização de Luis Maffei. Rio de Janeiro: Oficina Raquel, 2007.

QUINTAIS, Luis. Portugal, 0, vol. 3. Seleção e organização de Luis Maffei. Rio de Janeiro: Oficina Raquel, 2008. p.88-89

WINKLER, Heinrich August. Entrevista ao jornal Die Zeit, n. 52.17 de dezembro de 2008. p.64

MORETTI, Franco. Atlas do Romance Europeu; 1800-1900. São Paulo: Boitempo, 2001. 